Submission ID: 43824

\title{
Oil and Gas Content Analysis of the Tectonic Blocks of the
}

Srednemessoyakhsky Shaft

E.A. Potapova (OOO "TNNC"), L.A. Dubrovina (OOO "TNNC"), Y.V. Loshachenko* (OOO "TNNC")

\section{SUMMARY}

There are more than one hundred reservoirs discovered within the Srednemessoyakhsky shaft and the great majority of them are tectonically screened. Due to uneven distribution of the oil and gas reservoirs over the tectonic blocks this work presents the prospectivity estimation of the undrilled tectonic blocks based on both definition and analysis of main productivity criteria for any blocks. 
Анализ факторов, влияющих на нефтегазоносность тектонических блоков Среднемессояхского вала

Потапова Е.А. (ООО «ТННЦ»), Дубровина Л.А. (ООО «ТННЦ»), Лошаченко Ю.В* (ООО «ТННЦ»).

\section{Введение}

В пределах Среднемессояхского вала выявлено более ста залежей, из них подавляющее число с тектоническим экранированием. Поскольку распределение залежей УВ по тектоническим блокам достаточно неравномерно, в данной работе выполнена оценка перспективности неразбуренных тектонических блоков на основе выявления и анализа основных критериев продуктивности для того или иного блока.

\section{Постановка задачи исследования}

Большехетская впадина и Мессояхский пояс валов являются крупными тектоническими элементами северо-востока Западной Сибири, к которым приурочены значительные скопления углеводородов. Мессояхский пояс валов является особой надпорядковой структурой, представляющей собой систему валов субширотного простирания, которая разделяет НадымТазовскую и Карско-Гыданскую синеклизы и вместе с ними образует Ямало-Тазовскую мегасинеклизу - крупнейшую и наиболее прогнутую часть Западно-Сибирского бассейна. В центральной части пояса выделяется самый высокоамплитудный в Западной Сибири Среднемессояхский вал, осложненный Западно-Мессояхским и Восточно-Мессояхским локальными поднятиями.

Особенностью геологического строения Среднемессояхского вала является широкое развитие в его пределах дизъюнктивных дислокаций. Преобладающими структурными элементами, образовавшимися в результате разрывных смещений, являются горсты и грабены.

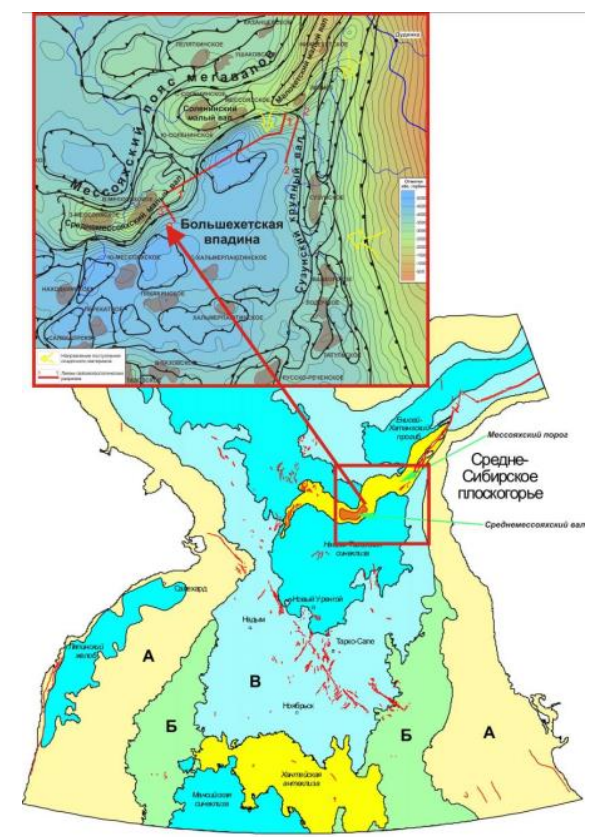

Рисунок.1. Тектоническая карта мезозойско-кайнозойского ортоплатформенного чехла Западной Сибири (Бочкарев В.С. и др., 2001г.)

В пределах вала промышленные притоки нефти и газа получены из 34 пластов, в разрезе приурочены к различным нефтегазоносным комплексам (НГК): нижненеокомскому, 
верхненеокомскому, аптскому, альб-сеноманскому. По материалам последнего подсчета запасов в пределах вала выявлено более ста залежей, из них подавляющее число с тектоническим экранированием. Поскольку распределение залежей УВ по тектоническим блокам достаточно неравномерно, то актуальной является оценка перспективности неразбуренных тектонических блоков на основе выявления и анализа основных критериев продуктивности для того или иного блока.

\section{Анализ влияния типа тектонических дислокаций на нефтегазоносность}

В пределах вала выделено два типа дизьюнктивных дислокаций: сбросы - плоскость разлома наклонена в сторону опущенного крыла; взбросы - разрыв с крутопадающим сместителем, по которому висячее крыло поднято относительно лежачего (рис.1).

От типа дизьюнктивной дислокации во многом зависит сохранность залежей.

В зонах растяжения, как правило, образуются сброшенные блоки (грабены). В этом случае ограничивающие блок нарушения располагаются V-образно по отношению друг к другу, образуется небольшое растяжение пластичных пород покрышки, разрушение не происходит, экранирующие свойства сохраняются, пониженное давление в зоне растяжения вызывает приток УВ. В зонах сжатия, образующихся в приподнятых блоках (горстах) при Л-образном положении ограничивающих блок нарушений, наоборот возникает нарушение целостности экранирующих пород, разрушение залежи и перемиграция УВ по восстанию. Помимо этого увеличение капилярного давления в зонах сжатия приводит к трудности отделения нефти от воды на фазовом уровне, что снижает дебиты в скважинах. [1]

На рисунке 2 представлена структурная карта по ОГ Н2 (поздний валанжин), где указаны направления падения опущенного крыла, а также обозначены блоки являющиеся сбросами, как наиболее перспективные.

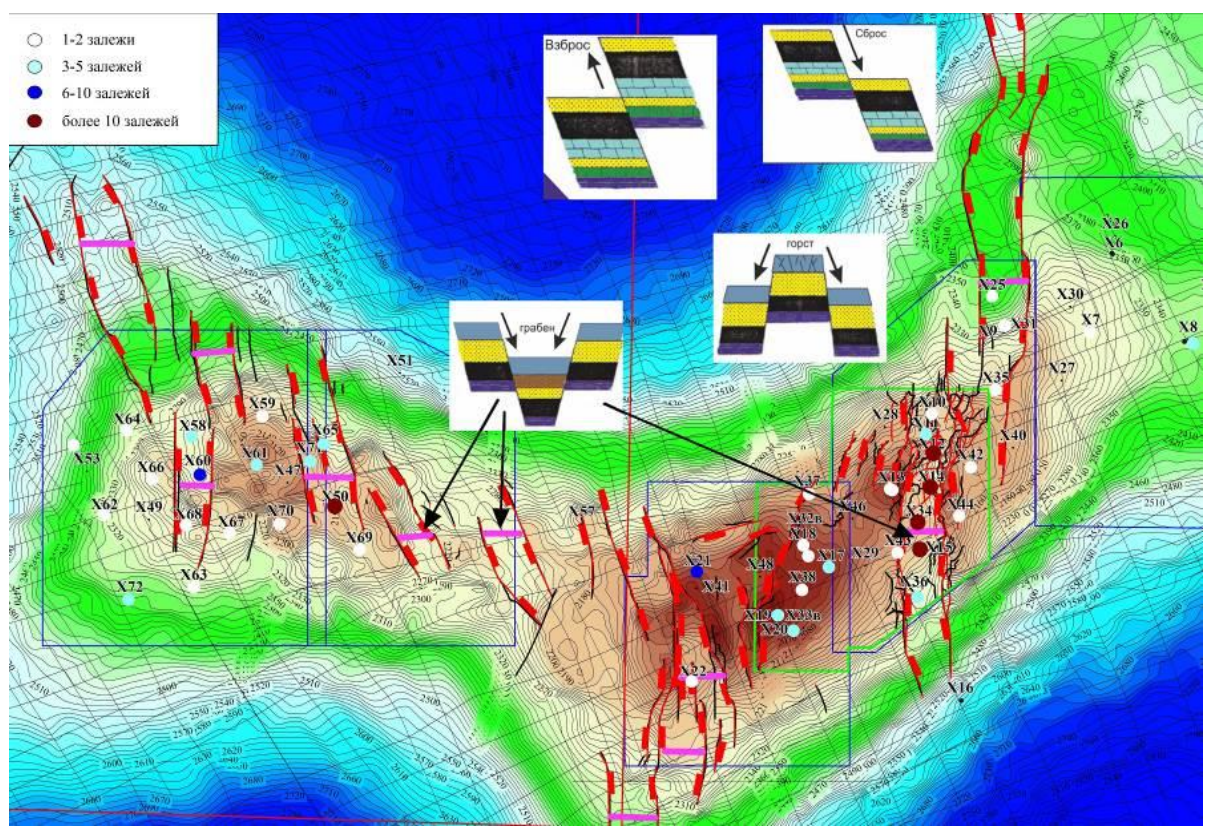

Рисунок 2. Анализ распределения УВ по тектоническим блокам

В пределах всей территории выполнен анализ количества залежей, вскрытых скважинами. Всего на территории выделено около 10 крупных блоков сбросового типа. Область концентрации запасов по разрезу (свыше 10 залежей) наблюдается в блоке, вскрытом скважинами X15, X34, X14, который отнесен к сбросовому типу нарушений. 
В целом, исходя из анализа, можно определить следующие критерии оценки перспективности тектонических блоков по структурному фактору: наличие замыкающейся структуры в пределах блока, значительные амплитуды, сбросовый тип тектонического блока, отсутствие внутренних деформаций.

\section{Анализ влияния палеотектоники на наличие и сохранность залежи}

Помимо этого была предпринята попытка оценить время образования системы разломов и влияние этого фактора на факт существования залежей в блоке (скопление УВ и степень сохранности ловушки). Анализ карты временных толщин интервала T4-H2 показывает, что процесс накопления осадков в пределах Среднемессояхского вала в неокомское время проходил в условиях отсутствия значительной раздробленности (мощности отложений опущенных блоков практически равны мощностям в приподнятых областях).

Существующая система разломов, скорее всего, была окончательно сформирована в палеогененеогене. Согласно этому утверждению структурные ловушки, сформированные на начальном этапе, должны были быть разрушены, либо разбиты на отдельные части. Помимо этого нефтематеринские породы остаются в главной фазе нефтегазообразования и после глобальных тектонических перестроек, соответственно идет дальнейшая генерация УВ и локализация залежей в тектонических блоках. Оценка этого предположения также произведена по степени заполнения существующих ловушек. Коэффициент заполнения структурных ловушек группы пластов БУ13-14 составляет 75\%, группы пластов БУ6-11 - 60\%, ПК20-МХ9 - 35\%, ПК8-12 $25 \%$. Тенденция к снижению коэффициента вверх по разрезу может быть объяснена постепенным погружением территории. Так же влияет удаленность нефтематеринских пород от принимающих резервуаров.

Интересным фактом остается то, что степень заполнения и площади ловушек в пласте ПК1-3 выбиваются из этой статистики. Коэффициент заполнения здесь равен $60 \%$. Этот факт может быть объяснен тем, что нефтематеринские породы для этого интервала расположены в непосредственной близости, в сочетании с мощными коллекторами пластов ПК1-3 и хорошими ФЕС, скорость заполнения ловушек была несколько выше нижележащих отложений. Так же не стоит исключать тот факт, что после тектонических деформаций, разрушенные залежи по разрезу переформировывались, и миграция УВ осуществлялась вдоль разломов в направлении пониженных давлений.

\section{Выводы}

- Наиболее перспективными для поиска структурно-тектонических залежей в изучаемой области являются тектонические блоки сбросового типа с наличием замкнутого поднятия со значительной амплитудой, с отсутствием внутренней раздробленности. Наиболее вероятным в таких условиях будет являться наличие значимых залежей в пластах ПК1-3;

- На рисунке 3 выделены перспективные блоки, в которых возможно существование нескольких залежей в различных пластах. Форма и размер ловушки по каждому конкретному пласту в данном случае в большей степени контролируется современным структурным планом соответствующего горизонта;

- Зоны 1 и 2 являются наиболее перспективными по неокомской части разреза, так как расположены в присводовой части вала, соответственно образуют амплитудные структуры по всем горизонтам этого интервала (рис. 3);

- По группе пластов ПК в соответствии с выявленными критериями оценки тектонических блоков, не разбуренных скважинами и отвечающим всем требованиям, не было выявлено. Тем не менее, с учетом особенностей заполнения ловушек в пласте ПК1-3, здесь перспективными областями могут являться структуры в приподнятых блоках. На рисунке 4 выделено 5 таких зон; 


\section{EAGE}

EUROPEAN

ASSOCIATION OF
GEOSCIENTISTS \&

ENGINEERS

- $\quad$ По рекомендациям была заложена скважина Y в зону 2 по пласту ПК1-3. В настоящий момент скважина находится в бурении. На сегодняшний день из интервала пласта ПК13 наблюдаются выпоты нефти (испытания еще не проводились). По всем признакам интервал можно считать продуктивным.

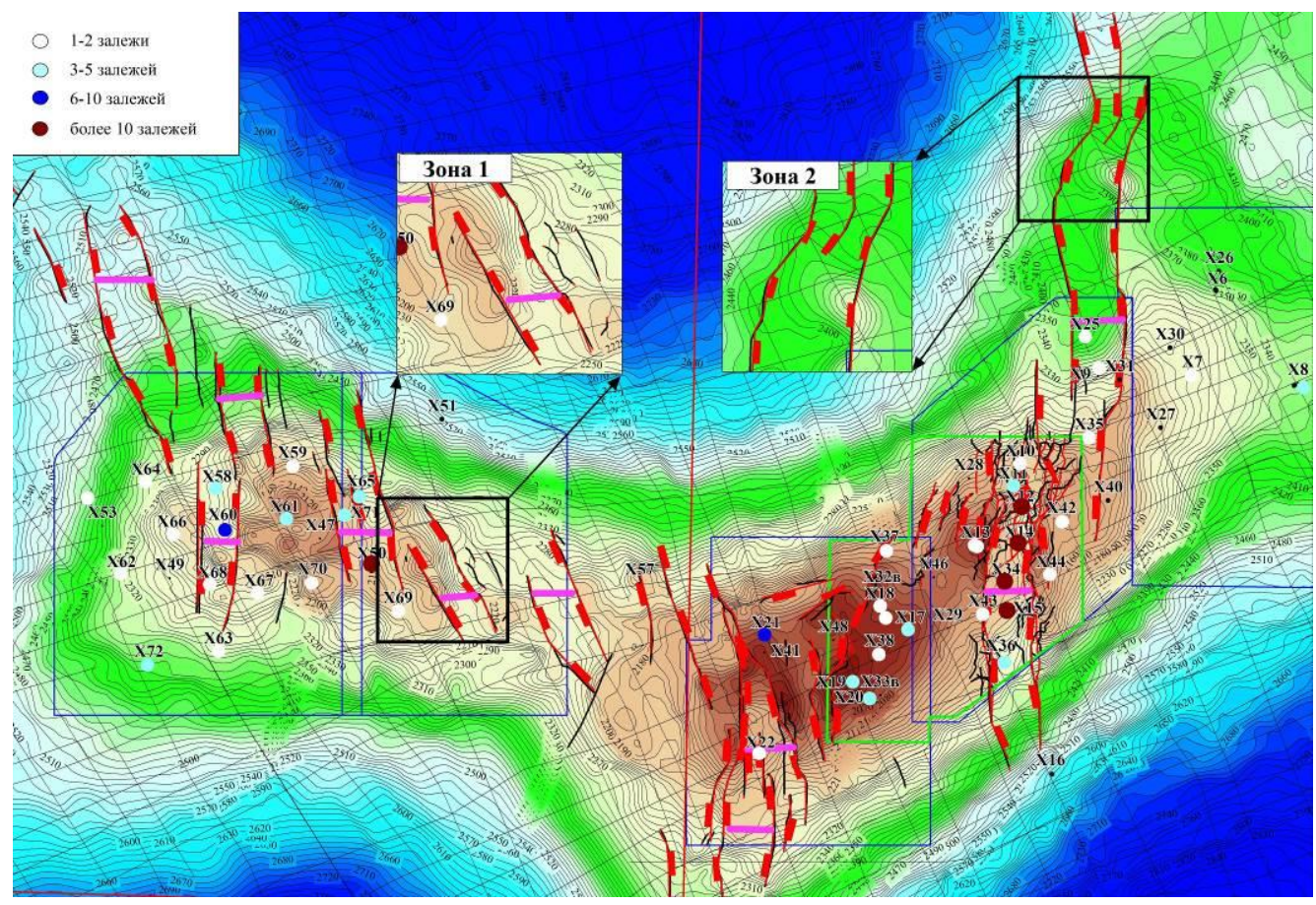

Рисунок 3. Перспективные зоны по группе пластов неокома

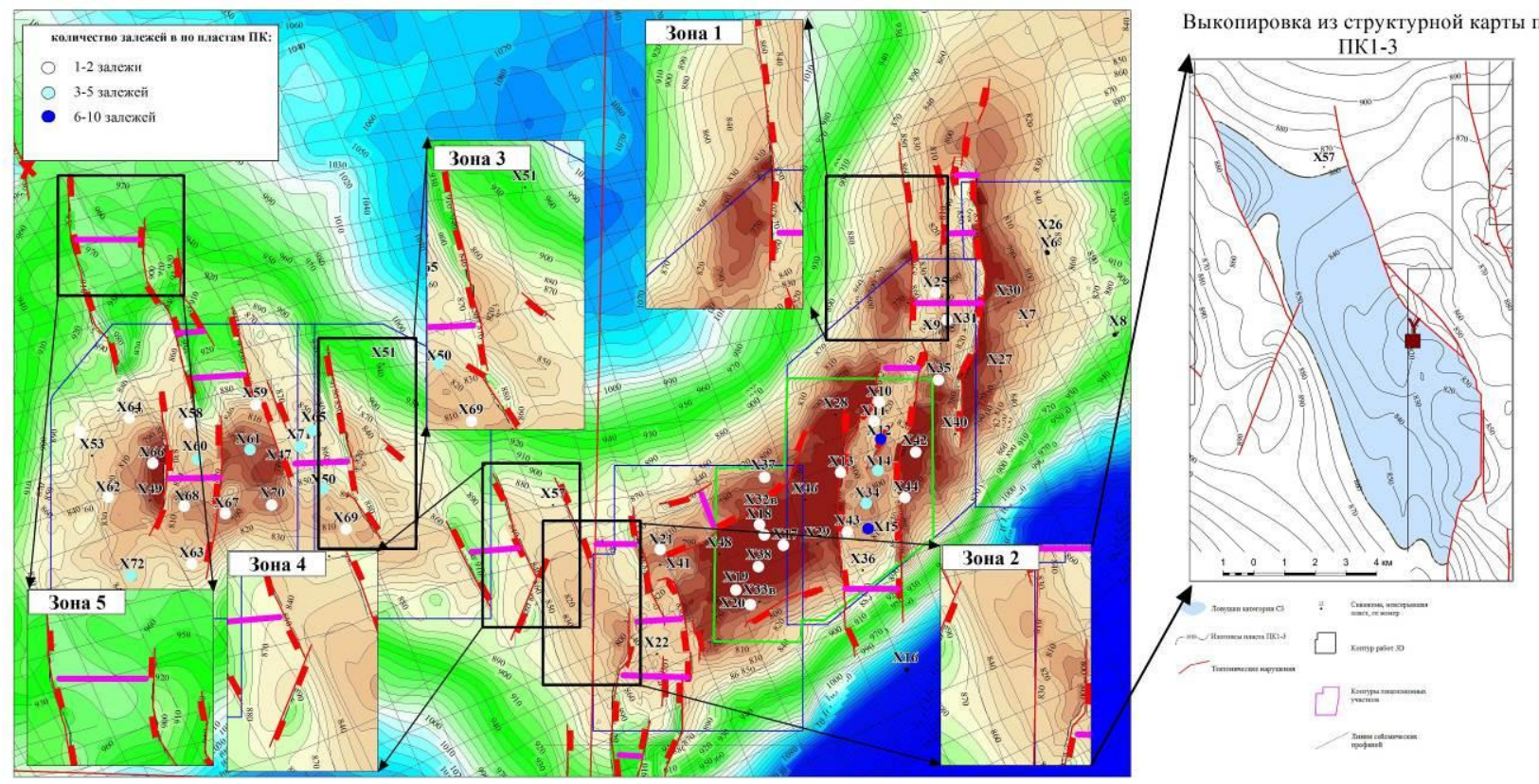

Рисунок 4. Перспективные зоны по группе пластов ПК1-3

\section{References}

1) Professor Ken McClay. Structural Analysis MSc Petroleum Geoscience. Royal Holloway University of London. 2010, C-503 